\title{
I Encontro Nacional de Rap e Repente: à procura pela rima entre identidade e alteridade
}

\author{
Karlla Christine Araújo Souza
}

resumo $\mathrm{A}$ mudança nos processos de Identidade é parte de uma mudança mais complexa na sociedade, por isso, enfatizamos a Identidade como um movimento de transformação, apreendida enquanto processo, e náo como ponto fixo de elaboração. Uma outra discussão acerca das identidades culturais considera o movimento de "hibridação", que a partir do conflito entre os empréstimos e contatos culturais remete a uma reflexão sobre Identidade e Diferença. Portanto, iremos utilizar o exemplo do I Encontro Nacional de Rap e Repente para analisar como a Identidade é produzida por meio das inter-relaçóes sociais e, através dos relatos dos rappers e repentistas, considerar as propostas de políticas culturais do Ministério da Cultura que prevêem pontes de comunicaçáo entre diferentes culturas, negligenciando os aspectos da diferença e da diversidade cultural.

palavras-chave Identidade. Diferença. Diversidade. Hibridação. Conflito.

\section{Introdução}

É comum falar-se em identidade relacionada a pessoas, culturas, naçóes, regióes, etnias, gênero, etc. Todavia este é um debate relativamente novo nas Ciências Sociais, que responde não apenas às mudanças nas expressões sócioculturais de protesto e reivindicação, mas, sobretudo, às modificações na forma de abordá-las teoricamente. Paulo Henrique Martins, em conferência magistral do XIII Encontro de Ciências Sociais do Norte e Nordeste - CISO
(Martins, 2007), ressalva que as ciências sociais foram também impulsionadas à renovação de seu aporte teórico seguindo o caráter do processo de globalização e acrescenta que categorias como "classes sociais" e "sujeitos históricos" não dão conta de explicar satisfatoriamente mudanças inéditas nas práticas e políticas sociais.

Na perspectiva de Hall (2000; 2004; 2006), os processos de identidade têm se caracterizado pelo predomínio da fragmentação, descentramento e deslocamento, graças ao fenômeno da globalização. Neste caso, a mudança nos processos de Identidade é parte de uma mudança mais complexa na sociedade. Por isso, as adequaçóes que as identidades têm sofrido no campo teórico (por alguns chamada de crise) acompanham os reflexos das transformaçóes da cultura de um modo geral.

Malgrado o desenvolvimento de toda uma discussão teórica, o conceito de Identidade ainda não foi definido com exatidão. Não é parte dos nossos esforços empenharmos-nos em suplantar esta lacuna, mas enfatizarmos a Identidade como um movimento de transformação em detrimento da definição "daquilo que é", ou seja, a Identidade apreendida enquanto processo, constante movimento, e náo como ponto fixo de elaboração. Através da nossa observação empírica, constatamos que ela é produzida por meio das inter-relações sociais.

Teoricamente, apreendemos que a Diferença é fundamental para compreendermos os processos de elaboração da Identidade. Destarte, procuramos trabalhar com um sentido mais 
amplo de Identidade, que não tem significação numa simples oposição binária entre o "eu" e o "outro", "igual" ou "diferente", mas num sentido da diferença que nunca está completo, não se encerra em oposições fixas. Ao invés disto, permite que a identidade cultural esteja sempre aberta para sentidos suplementares.

Por fim, acompanhamos um debate acerca do Multiculturalismo e seu papel na relação entre Diversidade, Identidade e Alteridade, a fim de compreendermos o recente empreendimento do Ministério da Cultura na área de políticas culturais com o I Rap e Repente, encontro de rappers e repentistas que aconteceu na Cidade de Campina Grande-PB entre os dias 26 e 28 de outubro de 2007.

Embora previsto com um ano de antecedência, o evento fez parte da agenda social do Governo Federal inaugurada com o programa Mais Cultura no dia 04 de outubro de 2007. Um dos objetivos explícitos do Mais Cultura consiste em promover a diversidade cultural através da criação de políticas públicas para a cultura, garantia de acesso aos bens culturais e geração de oportunidades de emprego e renda. Por isso, a programação oficial do evento preocupou-se em reunir o então Ministro da Cultura, Gilberto Gil, com os gestores dos municípios paraibanos para discutir e articular as novas políticas voltadas ao setor cultural. $\mathrm{O}$ ministro também participou como palestrante do Seminário Tradição e Contemporaneidade.

No geral, a programação do evento incorporou uma miscelânea de atividades e atrações artísticas às quais o público teve acesso gratuito, dependendo apenas de uma inscrição. Todavia a dificuldade de acesso deu-se graças à localização do evento, que aconteceu na distante casa de espetáculos Spazzio. A programação foi dividida entre oficinas, seminários, mostra de dança, vídeo e cinema, exposição de cordel, um festival de violeiros e shows com artistas pouco conhecidos e/ou consagrados. Entre as oficinas o público dispôs de aulas de xilogravura, cordel, grafitti, rima, discotecagem, dança de rua. Entre os seminários, pudemos destacar De Nova Iorque às Periferias Brasileiras. O Processo de Inserção do Hip Hop no Brasil, com o palestrante do movimento Hip Hop Nino Brown; O Rap da Cantoria e o Repente do Rap. Semelhanças, Dessemelhanças e Desafios, com o escritor Bráulio Tavares; e o Seminário Plano Nacional de Cultura, com o secretário de Políticas Culturais do Ministério da Cultura (MinC), Alfredo Manevy, o secretário de Identidade e Diversidade Cultural do MinC, Sérgio Mamberti e a Subsecretária de Cultura do Governo do Estado, Daniella Ribeiro. O Ministério da Cultura e o Governo do Estado foram os principais realizadores deste evento, com o apoio cultural da Petrobrás.

Compondo a grade da programação musical houve a apresentação de artistas populares como Baixinho do Pandeiro (PB), As Ceguinhas de Campina Grande (PB), Selma do Coco (PE), Lia de Itamaracá (PE) e Caju e Castanha (PE). Entre os artistas de Hip Hop tivemos o grupo Marechal (RJ), Zé Brown (PE), Nelso Triunfo (PE), Projeto Binário (PB). Compondo as atraçóes de destaque nacional apresentaram-se Cidade Negra, GOG, Funk \& Cia, Gabriel O Pensador, Cabruêra e Z'africa Brasil.

Pela configuração da programação, destacamos de antemáo que a proposta de coalizáo entre a literatura de cordel, a embolada e o repente de viola, misturando-se à dança de rua, ao grafitti e ao hip hop e junto a atraçóes populares de massa como Cidade Negra e Gabriel O Pensador compôs um verdadeiro pacote artístico rotulado pelo nome de diversidade.

A participação dos violeiros limitou-se a uma apresentação de Oliveira de Panelas na abertura oficial, onde fez alternância com a rapper paraibana Kalyne Lima, parceria já experimentada um mês antes no show "Vice-Versa" realizado em João Pessoa, capital paraibana. No segun- 
do dia do evento aconteceu também um Congresso de Violeiros onde disputaram seis duplas de cantadores, dentre os quais cinco foram por mim entrevistados na ocasião do evento.

Pretendemos construir uma visão deste evento a partir da fala dos improvisadores profissionais do repente da cantoria e do repente do rap, olhando a situação com enfoque nos atores principais deste megaevento, a fim de entender suas semelhanças e diferenças culturais e, então, fazer uma breve análise sobre as intenções e os êxitos de um empreendimento que pretende unir Identidade e Diferença na prática efetiva do encontro entre as culturas.

\section{Identidade e globalização}

É necessário distinguir os processos econômicos da globalização do que ocorre no domínio específico da cultura. Para a economia mundial, a imagem de uma aldeia global pode ser facilmente visualizada graças aos equipamentos tecnológicos, aos aparelhos de comunicação e aos meios de transporte que nos permitem conceber o planeta como uma totalidade integrada. Porém, na esfera da cultura, quando paramos para analisar essa totalidade, o que constatamos é a ideia da diferença. A questão crucial à qual devemos nos submeter é a da formação das Identidades políticas, sociais e culturais. Em outras palavras, devemo-nos perguntar como surgem os processos de Identidade neste mundo integrado.

Homi Bhabha acena para uma rearrumação no cenário mundial que aponta para um redimensionamento do papel do estado-nação e um realinhamento das fronteiras culturais:

O que é impressionante no novo internacionalismo é que o movimento do específico ao geral, do material ao metafórico, não é uma passagem suave de transição e transcendência. Cada vez mais as culturas 'nacionais' estão sendo produzidas a partir da perspectiva de minorias destituídas. O efeito mais significativo desse processo não é a proliferação de 'histórias alternativas dos excluídos', que produziram, segundo alguns, uma anarquia pluralista. $\mathrm{O}$ que meus exemplos mostram é uma base alterada para o estabelecimento de conexôes internacionais (Bhabha, 2007, p. 25).

Até mesmo as propostas da UNESCO (Organização das Naçóes Unidas para a Educação, a Ciência e a Cultura) têm exigido das naçôes novos posicionamentos em relação à sua formação cultural. Ao passo que vem estimulando a criação, produção e difusão de bens culturais, com vistas à abertura do diálogo entre as culturas e à promoção do acesso equitativo à diversidade das expressóes culturais provenientes do mundo todo (UNESCO, 2006).

Enxergamos neste debate mundial um avanço em relação ao compromisso político e ético do direito às diferenças. Mas acreditamos que a globalização é um fenômeno que perpassa múltiplas dimensóes, e os desníveis entre as dimensóes da economia, da tecnologia e da cultura geram ambientes de conflitualidade. Além disso, as novas relaçôes interferem no conteúdo histórico por meio do qual as identidades vinham sendo construídas. Este fenômeno é o que muitos autores têm identificado como crise da modernidade e Stuart Hall (2002) definiu como crise da identidade. A crise à qual o autor se refere consiste na ruptura com as formas de identidade que foram construídas em períodos históricos anteriores e com os processo sociais que lhes deram sentido.

Os antigos processos tinham em comum o caráter unificado de suas identidades, o passado, a tradição, a região de origem, e estariam sendo substituídos por processos de fragmentação. $\mathrm{O}$ processo de globalização é assim observado como responsável pelas transformaçôes 
sociais e culturais que se intensificaram nas últimas décadas. A globalização tem sido conhecida por revelar processos e práticas que têm perturbado o caráter relativamente estável de muitas populaçóes e culturas. Num tempo de identidades fragmentadas, póem-se em questão uma série de certezas firmadas.

A teoria crítica desconstrutivista tem transitado entre o pós-estruturalismo, o pós-colonialismo e o pós-modernismo. No entanto, ela se unifica enquanto novo olhar aplicado sobre a problemática da identidade no mundo globalizado e o questionamento do pensamento iluminista que caracterizou a modernidade. Paulo Henrique Martins (2007) acredita que alguns autores dos Estudos Culturais defendem uma interpretação errônea da crítica da modernidade, supondo uma ruptura entre os dois imaginários, moderno e pós-moderno, estrutural e pós-estrutural, etc. $\mathrm{O}$ autor não enxerga uma discrepância entre um grupo e outro, desde que ambos estejam voltados para repensar os fundamentos filosóficos, morais e políticos da modernidade. Defende ainda uma teoria sobre a globalização que se comprometa com o interesse prático da universalidade dos valores humanos e com as particularidades de cada cultura.

Isto posto, partimos da ideia de que existem de fato mudanças no imaginário coletivo e que elas devem indicar os caminhos que nos permitam visualizar as mudanças do mundo moderno. Alem disso, trabalhamos o conceito de Identidade dentro da linha dos estudos culturais, que admite a existência das Identidades a partir da relação com as Diferenças.

\section{Identidade e diferença - uma visão teórica}

Para o antropólogo Stuart Hall (2002), as velhas identidades responsáveis pela estabilidade da antiga ordem social estão sendo substituídas por novas, caracterizadas entre outras coisas pela fragmentação. Hall compreende que o sujeito pós-moderno é portador de identidades descentradas, deslocadas. Ele é obrigado a romper com as circunstâncias que lhe davam apoio, parecendo, em alguns momentos, que lhe falta um eixo; diferentemente ocorre com o sujeito da sociedade "liberal-iluminista", este tem a oportunidade de fixar-se sobre justificativas de ordem histórica, tais como tradição, passado e experiências compartilhadas. Dito de outro modo, na Era Moderna o indivíduo encontra sua identidade ancorada em apoios estáveis, enquanto na Modernidade Tardia o sujeito passa por um profundo processo de descentramento.

No livro A Ideia de Cultura Terry Eagleton levanta uma crítica acerca da noção de fragmentação e afirma que a cultura pós-moderna acomoda tanto o culto ao descentramento, quanto a política de identidade/comunidade. Para o autor, experimentos em relação à origem e a temporalidade passada, à tradição e à ancestralidade podem ser fonte de admiráveis progressos em experiências de "democracia popular", mas também têm sido responsáveis por extremados exemplos de "fanatismo". Conforma-se, desse modo, um mundo no qual alguns estão por demais seguros de quem são, enquanto outros estão demasiadamente confusos e inseguros (Eagleton, 2005).

Uma outra discussão acerca das identidades culturais face à globalização remete-nos ao termo "Culturas Híbridas", que leva a uma perspectiva de identidade cultural formada por diversas outras representaçôes. As culturas híbridas surgem como interseções imprevisíveis, uma colcha de retalhos dentro de uma malha abrangente, o lugar em que novas redes de relaçóes têm sido constituídas em meio às possibilidades do mundo integrado culturalmente. A respeito dos processos de hibridização, Hall ressalta:

Em toda parte, estão emergindo identidades culturais que não são fixas, mas que estão sus- 
pensas, em transição, entre diferentes posiçóes; que retiram seus recursos, ao mesmo tempo, de diferentes tradições culturais; e que são produto desses complicados cruzamentos e misturas culturais que são cada vez mais comuns num mundo globalizado. (Hall, 2000, p. 88).

Sua concepção aceita que "[...] as identidades não são nunca unificadas, que elas são na modernidade tardia, cada vez mais fragmentadas e fraturadas" (Hall, 2004, p. 108) e admite que as relaçóes que estão por trás das definiçóes de identidade "[...] não são, nunca, singulares, mas multiplamente construídas ao longo de discursos, práticas e posiçôes que podem se cruzar ou ser antagônicas" (Hall, 2004, p. 108). De onde podemos inferir que a hibridação seria uma extensão da fragmentação cultural, construída a partir dos entrecruzamentos de diversos grupos históricos e sociais.

Segundo Tomaz Tadeu da Silva, os processos de hibridismo são aqueles que ousam cruzar as fronteiras entre o "nós" e o "outro". Porém, cruzar as fronteiras significa, em alguns casos, "não respeitar os sinais que demarcam - 'artificialmente'- os limites entre os territórios" (Silva, 2004, p. 88). Tal perspectiva aponta para as relaçôes de conflito ocultas por trás da hibridização. Por isso, devemos ter em mente que as intersecçóes entre as culturas às vezes aparecem conflitantes graças aos pontos de apoio que devem buscar. Clifford Geertz nos alerta:

Para viver numa colagem, é preciso, em primeiro lugar, que a pessoa se torne capaz de discernir seus elementos, determinando quais são (o que implica, em geral, determinar de onde vieram e o que eram quando estavam lá) e como se relacionam uns com os outros [...] (Geertz, 2001, p. 81).

É ingenuidade acreditarmos que a hibridização se dá de modo harmonioso, pacífico e generoso pela troca entre as culturas. Essa visão incauta de que diferentes mundos culturais são táo bons, tanto uns quanto outros, acaba por gerar uma concepção ilusória da hibridização, o que

conduziria a um mundo cujas culturas todas apaixonadas umas pelas outras, aspirariam apenas a celebrar-se mutuamente, numa tal confusão que cada uma perderia qualquer atrativo que tivesse pelas demais e perderia sua própria razão de ser (Geertz, 2003, p. 71).

Essa problemática conduz diretamente à ambivalência entre Identidade e Alteridade. No campo teórico, uma saída é tratar a Identidade Cultural através da Diferença e migrar de uma visão essencializada das posiçóes identitárias em favorecimento de uma visão dialógica e não-definitiva. Mormente, a noção de identidade trazia a ideia de algo idêntico, considerando a repetição do comportamento como traço peculiar e predizendo uma suposta imutabilidade do modo de ser. Teoricamente, o conceito evoluiu para a noçáo da Identidade como um conjunto de expectativas internalizadas, comuns a determinados indivíduos.

Entendemos que a Identidade é o ponto a partir do qual surge a percepção de si. Porém, não devemos incorrer na noção de Identidade como semelhança, como exclusivismo, do tipo "nós somos nós" e "eles são eles", e propor uma noção menos rígida e fechada dos processos de formação e constituição da Identidade. Pois, ao mesmo tempo em que as semelhanças estabelecidas nas referências a priori têm a função de formatar a identidade cultural, também as diferenças têm um papel preponderante nos sistemas de representação.

A diferença diz respeito àquilo que é exterior, que não nos pertence, mas que, em verdade, complementa o sentido de Identidade. Por um lado, a identidade é reforçada por meio de ritos, rituais e códigos em comum, que atualizam os significados partilhados. Por outro, a 
marcação da diferença favorece a autopercepção de si, em que o outro é visto como uma fonte rica de significados, a partir do exemplo do que não queremos ser.

Woodward sugere a Identidade como a linguagem do "nós" e a Diferença como o aspecto da Identidade que diz sobre os nossos lugares no mundo. Neste caso, a Identidade é vista não como o oposto da diferença, mas interligada a ela, já que em algum momento "a Identidade é formada a partir da relação com o que não e’"(Woodward, 2004, p. 39-40). Conforme alerta Lévi-Strauss, "[...] a diversidade resulta do desejo de cada cultura de resistir às culturas que a cercam, de se distinguir delas - em suma, de ser ela mesma” (Lévi-Strauss apud Geertz 2001, p. 71).

Para Tomaz Tadeu da Silva, a diferença é também este lugar onde o "particular" conversa e inter-relaciona-se com o mundo, no sentido de que: "Só precisamos afirmar o que somos, porque existem outros seres que não são iguais a nós" (Silva, 2004, p. 75). Reforça ainda que: "Em um mundo imaginário, totalmente homogêneo, no qual todas as pessoas partilhassem a mesma Identidade, as afirmaçóes de Identidade não fariam sentido" (Silva, 2004, p. 75).

Assim como a língua é um sistema coletivo e não individual, também as palavras ganham significado por meio das relaçôes sociais. De tal modo, os processos identitários só fazem sentido por meio das orientaçôes externas e da relação com os outros. Marc Augé afirma que: “[É] sempre uma reflexão sobre alteridade que precede e permite toda definição de identidade" (Augé, 1997, p. 94). Nesse sentido, Stuart Hall reconhece que até mesmo as unidades que as identidades proclamam são construídas no interior de um jogo de fronteiras:

[...] por meio da diferença e náo fora dela. Isso implica o reconhecimento radicalmente perturbador de que é apenas por meio da relação com o Outro, da relação com aquilo que não é [...], que o termo identidade pode ser construído" (Hall, 2004, p. 110).

Portanto, sugerimos substituir o aspecto essencialista da Identidade pelo caráter dialógico, em que o "nós somos" depende da interação com "os outros". Todavia, não é apenas da linguagem, como querem alguns autores, mas também por meio do contato com a diferença que se estabelecem costumes em comum e se erigem Identidades, fronteiras do igual. Nesse sentido, a determinação das diferenças é essencial para firmar espaços:

As culturas não desconhecem uma às outras e, de vez em quando, até tomam empréstimos entre si; mas, para não perecerem, elas devem, sob outros aspectos, permanecer um tanto impermeáveis (Lévi-Strauss apud Geertz 2001, p. 71).

Geertz (2001) ressalta que a diferença jamais pode ser ignorada. Assim como as assimetrias não podem ser relegadas ao plano do exclusivismo ou da dessemelhança. Pelo contrário, a perspectiva da identidade como campo das diferenciações deve caminhar para a percepção da pluralidade das características humanas e sociais como características intrínsecas à existência. De modo que ou entendemos as diferenças contidas no fenômeno da diversidade cultural, ou caímos numa ideia vazia de pluralidade, que no dizer deste autor resume-se na acepção banal de “cosmopolitismo sem conteúdo".

É preciso encarar a Identidade não como um sistema rígido e fechado de elaboração de valores em comum, mas como um processo que depende da contingência. Afinal, não podemos esquecer que "os outros" são distintos de "nós", mas simultaneamente compartilham o mundo conosco. O problema é que o equilíbrio entre Diferença e Identidade é muito frágil. Difícil se faz mensurar a fronteira entre Diferença e antagonismo, o que depende, sobremaneira, do 
contexto da intercomunicação. A questão é saber se é possível haver a marcação da Diferença sem que haja inextricavelmente uma relação de "oposição", em que o "outro" importe apenas como aquilo que o "nós” não admite ser.

\section{Rap e Repente}

Antes de nos atermos propriamente ao I Encontro Nacional de Rap e Repente, devemos contextualizar essas duas formas de expressóes artísticas e fazer alguns esclarecimentos necessários à compreensão do compósito cultural que envolve Rap e Repente.

A origem do repente nordestino é ainda hoje controversa; muitos dizem que é uma herança da tradição medieval ibérica dos trovadores, mas essa opinião não é unânime. Outros fazem questão de apontar a preponderância das influências mouras e judaicas na formação desta cultura. O importante é que a tradição, que já se tornou secular, ganhou autonomia e hoje já pode ser chamada para legitimar outros tipos de poesia versejada e improvisada.

O poeta improvisador do repente nordestino acompanha a tradição da cantoria de viola, propriamente chamada de cantoria de pé-deparede $^{1}$. Sua característica poética é marcada pela luta versejada entre dois cantadores que se alternam, provocando ou completando um ao outro. $\mathrm{O}$ ápice desse estilo artístico-poético é o desafio, o mais conhecido do improviso, que testa a criatividade do poeta em dar respostas incisivas à provocação do parceiro. $\mathrm{O}$ público costuma julgar a capacidade do poeta através $\mathrm{da}$ mordacidade das respostas dadas às perguntas ou insultos instigadores do seu companheiro de viola, bem como aquele que tem maior conhecimento e desenvolveu os versos com mais desenvoltura (Souza, 2004).

A métrica do repente é muito complexa, existem diversas combinações de estilos rítmicos e terminaçóes frasais para ordenar a rima. A sextilha, por exemplo, é formada por estrofes de seis versos (ou seis linhas), em que a segunda linha deve rimar com a quarta e a sexta: ABCBDB. Existem também variaçóes da décima, que pode ser decassílaba (dez linhas de dez sílabas) ou setessílaba (dez linhas de sete sílabas). A décima é a métrica mais usual na poesia improvisada do repente e está ordenada do seguinte modo: o primeiro verso rimando com o quarto e o quinto; o segundo com o terceiro; o sexto com o sétimo e o décimo, e o oitavo com o nono. De modo que eles estão assim predispostos: ABBAACCDDC. Existe ainda as variaçóes rítmicas como o martelo alagoano, o galope à beira-mar e tantas outras. Outras variantes da décima estão inclusas nas deixas dos "Dez Pés de Queixo Caído", "Neste Brasil de Caboclo, de Mãe preta e pai João", "E o que é que me falta fazer mais? se o que eu fiz até hoje ninguém faz?", em que aparece no final de cada estrofe este estribilho. Também o Quadrão Perguntado é fortemente apropriado para o desafio entre cantadores. Mas, é o Martelo Agalopado a variante mais comumente utilizada para desenvolver o desafio.

A base instrumental do cantador é a viola de dez ou doze cordas e seu cantar é acompanhado por toadas de acordo com as variaçóes dos versos. A voz do cantador não é o critério principal de apresentação; já a rima, esta deve seguir rigorosamente os padróes da escrita formal das palavras e não a similaridade do som sufixal.

Para conhecer densamente o repente nordestino é importante saber distinguir entre os diferentes tipos de improviso. Maria Ignês Ayala observa que a cantoria de viola envolve um significativo número de adeptos e:

Seus produtores - conhecidos como cantadores, repentistas ou violeiros - não devem ser confundidos com outras categorias de poetas populares do Nordeste: escritores de folhetos e emboladores (Ayala, 1988, p.15). 
Diferentemente da literatura de cordel ou da embolada, a cantoria de viola persiste eminentemente pelo improviso. A poesia de cordel não pode ser considerada de improviso, pois ao ser transferida para o papel ela pode ser reelaborada, realinhada. Por sua vez, a embolada, ainda que faça parte de uma tradição oral, juntamente com a cantoria, também não pode ser considerada de improviso, pois os trechos já conhecidos de cançôes e declamações é que dão margem para pequenos desfechos de improviso. É como se fossem frases feitas com abertura para pequenas variaçóes, onde devem caber as improvisações.

Já na cantoria de viola, pela própria disposiçáo do ritual, o poeta é levado a criar em tempo real. Evidentemente, ele utiliza seu conhecimento prévio, porém, elabora o verso no momento, de acordo com o mote sugerido pelo público, que deve ser conhecedor das normas métricas de construção dos versos.

$\mathrm{Na}$ tradição da cantoria, o repente significa improviso que foi presenciado pelo público no momento de sua elaboração. Por este motivo, a palavra repente geralmente é utilizada para denominar a arte dos cantadores de viola em fazer poesia metrificada e improvisada no calor do momento. O poeta-cantador é sabedor da estrutura métrica; contudo, deve estar preparado para improvisar em cima de motes desconhecidos. Por outro lado, os temas são recorrentes: seca, sertão, saudade, paixão, mulher, atualidades políticas, acontecimentos históricos, etc.

Já o rap remonta suas origens étnicas à Jamaica, migrando para os Estados Unidos na década de 70. Na Jamaica, o movimento surgiu nos anos 60, a partir dos Sound Systems, que eram colocados nas ruas dos guetos jamaicanos para animar bailes, que serviam de fundo para o discurso dos protestos. Foi aí que surgiram as intervençôes dos MCs (mestres de cerimônia), que se pronunciavam em forma de canto falado e acompanhavam um ritmo musical, nes- te caso, o reggae. Nos Estados Unidos, a base musical do reggae foi substituída pela batida do funk. Atualmente o rap já se misturou com várias outras influências musicais, tais como o jazz e o soul.

A melodia que acompanha a poesia cantada é o Hip Hop, que ao ser tocada por um DJ (disc-jóquei) e acompanhada pelo $M C$, que se responsabiliza pela letra cantada, formam juntas (melodia e letra) o que se chama de Rap. Na verdade, o termo Rap é a sigla para a expressão Rhythm and poetry (Ritmo e Poesia). O rap faz parte da cultura Hip Hop, junto com o grafitti e a dança break. Se considerarmos isoladamente o jeito de cantar improvisando, este se chama free style. No Brasil este estilo de cantar improvisando ganhou grande notoriedade, e atualmente os Mcs participam até de rachas, disputas de free style onde um tenta ser melhor do que o outro, semelhante às disputas dos cantadores repentistas nas cantorias e nos congressos de viola.

O Rap rapidamente se difundiu pelas periferias em todo o mundo, sendo apreciado principalmente nos EUA, na França, no Japáo e no Brasil. O rap surgiu no Brasil na década de 80, na cidade de São Paulo. Na década seguinte migrou para grandes capitais como Brasília, Belo Horizonte e Recife. Nos dias de hoje o rap está incorporado no cenário musical brasileiro e saiu da periferia para ganhar o grande público. As letras revelam o cotidiano nas periferias das grandes cidades e tratam também de questóes como preconceito e racismo.

Como vimos, o Rap e o Repente têm histórias e origens distintas. Assim, a cantoria, que hoje é uma prática no auge de seus 150 anos, tem sido levada, por força da contingência, a estabelecer o diálogo com jovens nascidos nos anos setenta e oitenta. Tal demanda é familiar ao Repente, que vive constantemente o conflito entre tradição e renovação. Mas é muito mais peculiar ao Rap, pela liberdade que sempre teve 
em incorporar elementos musicais e rítmicos. O rap é fruto de uma época em que fomos ensinados a romper com o passado e viver o cosmopolitismo. Porém, a fim de não cair no risco da obsolescência, tem buscado na tradição do Repente os ensinamentos sobre persistência e continuidade.

Não é de hoje que a uniâo entre rap e repente foi proposta, muito embora ela tenha gerado encontros tímidos e poucos pontos de intersecção na prática, até ter ganhado notoriedade desde que passou a receber atenção do Ministério da Cultura. A princípio, esse diálogo parece difícil e forçoso. Na tentativa de encontrar elos, há quem forje a antecedência do Repente como fundador do Rap. Entretanto, seu ponto em comum se explica muito mais pelo caráter criativo e dinâmico do seu discurso na atualidade do que pela descendência cultural. Não é à toa que seu maior ponto de interseção encontra-se na prática do improviso.

De todo modo, não podemos esquecer que o improviso não é um discurso sem preparação, ele requer agilidade mental e vasto conhecimento lexical do improvisador, mas exige, sobretudo, o conhecimento da experiência e do contexto cultural que lhe dá forma e significado. Por isso, precisamos levar em conta as diferenças entre Rap e Repente para não olvidarmos as dificuldades que surgem na interação entre essas duas modalidades de fazer repente.

\section{Encontro Nacional de Rap e Repente}

A união entre Rap e Repente no contexto da política cultural do estado brasileiro já poderia ter sido proposta em outro momento institucional, pois em sua síntese, a procura por uma identidade nacional celebrou o popular enquanto símbolo de constituição da cultura brasileira, ocultando sob a égide de uma identi- dade totalizadora os conflitos e as questóes das diversidades regionais, de classe e de raça. Nesse sentido, tanto a cultura popular-tradicional do Repente quanto o Rap, símbolo da cultura negra, estariam marcados pela insígnia histórica da cordialidade e da convivência harmônica.

No entanto, essa interlocução foi interceptada num momento cultural caracterizado por uma nova política internacional, pela descentralização do poder dos estados-naçóes e pela fragmentação dos movimentos identitários. Por este motivo, a fusão do Rap e do Repente, neste contexto, toma outra conotação.

No Brasil, a questão da Identidade Nacional sempre passou pelo problema da diversidade, encerrando o dilema da unidade na diversidade. Outrora, o conceito da mestiçagem foi utilizado para resolver o problema de uma realidade cultural sem contradiçôes, o que nos legou o hábito de desconsiderar as divergências culturais em privilégio de uma imagem de cultura brasileira harmônica, sincrética, espontânea.

O Ministério da Cultura na gestão Lula/ Gilberto Gil procurou reconhecer o hiato entre as diferentes culturas regionais, étnicas, e as políticas identitárias ${ }^{2}$ de modo geral, e o tratamento dado pela política nacional. Pelo menos na instância dos discursos oficiais, inclusive publicizados em textos como Política Cultural no Brasil 2002-2006: Acompanhamento e Análise (Ministério da Cultura, 2007); bem como nas políticas pedagógicas, artísticas e econômicas, o governo federal traçou planos de açóes que partiam da constataçáo teórica da heterogeneidade e da fragmentação do campo de intervenção da política cultural no Brasil, o desgaste provocado por antigas tradiçóes institucionais e uma renovada promoção do fluxo de intercâmbios e experiências.

Um dos mais importantes programas do MinC na gestão Gilberto Gil foi o Programa Nacional de Cultura, Educação e Cidadania - 
Cultura Viva, que teve como metas a criaçáo dos Pontos de Cultura, a distribuição de livros, a modernização de bibliotecas e a implantação do Vale Cultura. Os pontos de Cultura, por exemplo, têm o intuito de promover o intercâmbio com projetos culturais historicamente excluídos e facilitar o fluxo de experiência e elaboração de identidades.

No âmbito nacional, o Ministério da Cultura criou a Secretaria da Identidade e da Diversidade, na esteira da discussão internacional compelida pela UNESCO que criou a Convenção sobre a Proteção e Promoção da Diversidade das Experiências Culturais, amplamente apoiada pelo Ministério da Cultura, contando inclusive com a compleição do ministro Gilberto Gil. Outra novidade desta gestão foi a proliferação de Seminários e Conferências, como é o caso do Seminário da Diversidade Cultural, realizado em diferentes estados nacionais, tais como Goiás, Minas Gerais e Paraíba.

A Convenção sobre a Proteção e Promoção da Diversidade das Experiências Culturais é uma extensão da Declaração Universal dos Direitos da Diversidade outorgada pela Unesco em 2002. Ela afirma que o respeito à diversidade das culturas é o caminho para a tolerância, a cooperação e o entendimento mútuo. Com esse direcionamento a Unesco acredita se colocar no centro de um debate contemporâneo e favorecer a solidariedade entre as naçóes. Portanto, uma de suas metas passa a ser o reconhecimento da pluralidade das identidades e o desenvolvimento dos intercâmbios culturais. Em suma, uma visão de alteridade que não condiz com a realidade dos Estados que se encontram fora de sua política.

O grande impasse dessa posição continua sendo a noção de diversidade, que tem como pressuposto a convivência pacífica e harmoniosa, o que contribui para construir uma visão de diversidade onde as identidades são neutralizadas, essencializadas. Onde não se toma conta dos conflitos que colocam em xeque as lógicas liberais. Exatamente o que pudemos notar na programação do encontro nacional de Rappers e Repentistas, que convidou à mistura dessas duas expressóes culturais para um encontro com a diversidade e colocou a cultura popular do repente como fundadora do sincretismo e da identidade cultural brasileira:

A programaçáo do Encontro Nacional de Rappers e Repentistas [...] mistura o sincretismo do Hip-Hop e a raiz tradicional do Repente, do Cordel e da Embolada. Com a participação de profissionais e artistas de todos os recantos do País, apresenta um leque versátil e rico de opçóes, como shows musicais, apresentaçóes teatrais, mostra de dança, cinema e vídeo, exposiçôes de xilogravura e cordel. Além de oficinas e seminários, que pretendem abordar e discutir a diversidade da cultura brasileira ${ }^{3}$.

No entanto, a narrativa do DJ Joh ${ }^{4}$ contradiz diretamente a conotação do discurso oficial:

Teve até indicaçóes aí do Estado de bandas assim, meio que impostas a tá no evento assim, é porque eu prefiro não citar nome pra não tá... mas teve imposição, teve banda que foi imposta, coisa de ligarem de última hora e dizerem: "Oh, essa banda tem que tá na programação, tá entendendo?” E uma banda que não tinha nem a ver com a temática do evento (DJ Joh).

Quando DJ Joh se refere ao Estado, ele está falando da representatividade do Governo do Estado da Paraíba. Logo, O MC e produtor George elucida sobre as brechas da institucionalidade e explica as falhas da equipe:

Eu acho que o grande problema do evento foi justamente esse. $\mathrm{O}$ evento ficou em mãos, assim, o maior poder de organização do evento foi dado a quem não conhece, assim, não tem 
conhecimento real do que é o rap, do que é o movimento hip hop, e muito menos do que é o repente. Então eu acho assim, que o evento foi um evento grande, foi um evento de nível nacional, veio gente de todos os cantos do Brasil, só que o evento deveria ter sido dado para gente que é interado, que é militante da cultura Hip Hop, que convive, que trabalha com o repente. Com poesia, enfim, com a cultura em geral (Frequência Zero).

A observação do DJ coaduna com a percepção do repentista Antônio Lisboa, que desabafa o que vivenciou como resultado dessa desinformação:

Acho que a coordenação não teve orientação para escolher as pessoas ideais para participarem das mesas, pessoas ideais para participarem dos debates e até na questão da divulgação e da colocação no palco, tanto em quantidade quanto em qualidade. Nós tivemos pouca representaçáo da cantoria e tivemos pouca qualidade na participação. A única coisa que pode salvar é a questão do Festival de Violeiros. Para você ter uma ideia, nas mesas, nos seminários, não aconteceu a participação massiva dos cantadores, na sua ampla maioria, nas suas cabeças de lideranças, nem nos debates das mesas, nem no palco também não teve a mesma quantidade. $\mathrm{O}$ palco foi destinado ao rap. Cada artista do rap que veio aqui tá bem divulgado, em tudo quanto é jornal, na programaçáo, cada folder tem o nome do artista, o horário, tudo organizado. $\mathrm{Na}$ questão da cantoria tem simplesmente o nome de um único cantador dentro da programação. Se essa programaçáo tivesse sido jogada com o nome dos cantadores, sem dúvida teria mais gente para prestigiar a cantoria. Náo vai ter, por quê? Porque as pessoas que estão vendo os debates, estão vendo os debates e não estão vendo a cantoria, porque na abertura não teve cantoria, então elas não vão saber que a cantoria vai ter aqui (Antônio Lisboa).
O problema da falta de formação qualificada para a gestão e difusão das políticas culturais já havia sido previsto pelo Plano Nacional de Cultura $^{5}$, que foi criado com o escopo de integrar as ações do poder público na produção e difusão de bens culturais. A frágil articulação entre os governos de nível federal, estadual e municipal também fora problematizada, prevendo até mesmo as tensões e conflitos que poderiam resultar da precária institucionalidade.

$\mathrm{Na}$ tarde de domingo, 28 de outubro, no horário reservado para apresentação dos repentistas, já nos portóes de entrada do Spazzio (local do evento), pude constatar a insatisfação dos cantadores, que sentados na calçada ainda não tinham sido convidados a entrar no espaço e não receberam sequer a recepção da produção. Ao adentrar no local, percebi que o público era mínimo, uma estrutura gigantesca que estava quase vazia, à espera da apresentação dos "donos da festa". Após algum tempo aguardando pela entrada dos repentistas, fui levada pelo cantador Vitorino - que estava do lado de dentro do Spazzio junto com Oliveira de Panelas - para o camarim onde os repentistas afinavam suas violas e se preparavam para subir ao palco. Em conversas com Antônio Lisboa, Rogério Menezes, Edmilson Ferreira, Raimundo Caetano e Lourival Vitorino, pude obter uma visão mais sistemática de suas experiências nesta proposta de Encontro.

O que eu já vi meus colegas criticando é que a propaganda desse evento tem o nome de Cabruêra, tem o nome de Oliveira de Panelas, "não sei o que", "não sei o que", "não sei o que", não tem o nome dos repentistas, não tem nem assim Festival de Violeiros, não tem. Quer dizer, dentro de um evento que é feito baseado no próprio repentista, onde talvez a força da cantoria de viola, do repente nordestino foi quem trouxe esse evento pra cá e fez que esse rap e repente viesse para a região do repentistas e não do rap. 
Aqui não tem grupo de rap, não tem, tem mais repentista. Entáo se teve esse patrocínio para o governo e o ministro fazer isso baseado na força do repentista, e o repentista não tinha nome nenhum no cartaz. Então tá todo mundo criticando... (Rogério Menezes).

O rapper Tiago Joh nos dá uma explicação para a supressão da participaçáo do repente que está calcada no panorama histórico das representações identitárias desprivilegiadas pela condição cultural de pertencerem a regióes geográficas tidas como periféricas, colonializadas e atrasadas:

Eu acho assim que o repente não apareceu tanto quanto o rap, primeiro por questáo cultural, de a gente menosprezar o que é da gente. Talvez se Jackson do Pandeiro e Elba Ramalho tivessem continuado aqui no Nordeste eles não iam ter a visibilidade que eles tiveram porque foram pro sul. Entáo a gente meio que tem vergonha, por essa questão que teve no passado, o que é moderno, o que é passado, considerado por muita gente coisa de velho (DJ Joh).

Oficialmente, nas palestras, mesas redondas, apresentações artísticas do palco principal, o discurso operante era o da harmonia. Nada de ansiedade, de conflito, de negociação. Tudo parecia já estar muito bem formatado: Rap e Repente são duas manifestaçóes marginais da cultura nacional e devem aproveitar o encontro para celebrarem seus traços em comum. Mas o que aconteceu de fato foi uma intercomunicação entre rappers e repentistas muito precária, limitada a encontros oficiais no palco principal, numa forma dissonante do que seriam as expectativas dos repentistas:

Porque o que tá sendo feito aqui é descaracterização do estilo, é um cantador que fez rap dizendo que é cantador e fez cantoria. Não pode ser, porque quando eu estou na modalidade da cantoria eu tenho que estar numa dupla de cantadores. Aí o que acontece se eu pego num microfone, subo sozinho no palco e vou cantar numa modalidade que não existe na cantoria. Então, eu tô, de certa forma, fazendo o rap, se eu tô fazendo rap eu não tô fazendo cantoria (Antônio Lisboa).

A impressão do MC Frequência Zero coaduna com o protesto do repentista Antônio Lisboa, confirmando a desvantagem do repente enquanto atração do evento:

O Encontro foi rap e repente, porque é como eu te falei, de repentista que eu me lembre eu acho que vi dois repentistas no evento todo, dois repentistas fazendo repente pro público, pra massa, que foi no Palco B. No palco principal teve a participação de Oliveira de Panelas e mesmo assim não foi um show de repente, foi uma pequena apresentaçáo. Entáo eu acho assim, que o evento era o encontro de rappers e repentistas, mas no fim das contas terminou sendo de rappers, foi mais um encontro nacional de rap e da cultura hip hop em geral (Frequência Zero).

Muito embora houvesse a abertura para a alteridade e, de certo modo, um interesse em comum, pois ambos, Rap e Repente, estão conscientes da força social dos denominadores interculturais da marginalidade e do protesto, não houve ambiente favorável, uma preocupação prévia que propiciasse as oportunidades inclusivas para as duas expressóes.

Acho... não tenho nada contra fazer esses eventos, fazer essas relaçôes, fazer essas ligaçóes sem existir o preconceito (pausa). O que eu acho que é interessante que cada um mantenha suas características. [...] Se for feita uma boa avaliação depois do evento, se for visto como ponto positivo o que é positivo e como negativo o que é negativo. Eu diria que precisa ser alertado para 
a questáo da cantoria não ter tido uma participação, na mesma voz em que houve uma participação do rap, aí pode acontecer. Agora, se acontecer mais dois eventos desses, que não tem nenhum cuidado com a cantoria, que dá pra ver que não teve, a tendência vai ser náo participar (Antônio Lisboa).

A ideia de uma diversidade fraterna é, em grande medida, herança do ideário Iluminista. O que está em jogo nesta empreitada do Ministério da Cultura é o fato de que não se ditam regras para se estabelecer os vínculos sociais e que a implementação do diálogo não implica no acordo alteritário. Em certo sentido, retroagimos a um problema instado na Revolução Francesa, isto é, o dilema entre liberdade/ igualdade, que promove a eliminação das assimetrias enquanto pressuposto da liberdade e a ampliação da interação enquanto pretensa garantia de igual dignidade. Vale ressaltar a crítica de Tomaz Tadeu da Silva:

$\mathrm{Na}$ perspectiva da diversidade, a diferença e a identidade tendem a ser neutralizadas, cristalizadas, essencializadas. São tomadas como dados ou fatos da vida social diante dos quais se deve tomar posiçốes. Em geral a posição socialmente aceita e recomendada é de respeito e tolerância para com a diversidade e a diferença. Mas será que as questóes da identidade e da diferença se esgotam nessa posição liberal? (Silva, 2000, p. 73).

Basta um breve olhar sobre a história política de nosso país para perceber que a ideia de favorecer o diálogo em lugar do conflito é uma atitude institucional que deixa fora do escopo da intervenção do Estado uma série de problemas econômicos, sociais e políticos. Nesse sentido, uma política de diversidade deveria enfatizar as diferenças como forma de reconsiderar o lugar histórico dos oprimidos que, não tendo o poder de impor suas diferenças, se sentem na necessidade de bradar gritos improvisados de protesto.

\section{Confronto entre identidade e diferença}

Seguindo a noção de identidade processual que propomos neste artigo, vemos que o respeito pelo "outro", pelo "diferente", é cada vez mais função do modo como são construídas e modificadas as interaçóes. Logo, o Rap e Repente constitui um exemplo profícuo para perceber questóes de Identidade e Diferença, como elas se articulam e ocorrem no contexto da interação social. A partir desta experiência tivemos a comprovação de que é no contexto social que surgem os mais variados modos de alternativas para construção da Identidade: "Não se pode afirmar uma identidade diferencial sem distingui-la de um contexto, e no processo de fazer a distinção, afirma-se o contexto simultaneamente" (Laclau apud Hall, 2003, p. 81).

O rap tem sido um dos elementos da chamada cultura popular urbana que, na realidade específica brasileira, vem atraindo uma grande quantidade de jovens das periferias das grandes cidades. Acostumado à dinâmica da globalização, o rap tem sido também um dos lugares onde ocorre a hibridação, os processos de reapropriaçáo. Enfim, o rap tem revelado os sinais do tempo e o espaço onde os atores reinventam suas práticas culturais, fortemente influenciados pelas novas tecnologias comunicaionais e suas possibilidades interativas. $\mathrm{O}$ caso do $\mathrm{Dj}$ Joh nos exemplifica essa tendência:

Hoje em dia o rap tá muito... Eu por exemplo, eu sou produtor, então eu posso lançar um disco com participação de vários MCs diferentes, internet, muito contato. Tem um som com o pessoal do Rio de Janeiro, O Quartel MC que foi eu que produzi, eu só mando a base musical pra eles, eles gravam a voz e lançam um CD pra lá mesmo (Dj Joh). 
Já o repente sofre por sua posição transitória de dupla inscrição na modernidade e na tradição. São artistas que ainda não suprimiram o anseio de perder as características próprias da tradição, que ainda se ligam a um território-região, aos rituais do passado e à herança cultural dos antecessores. Enfim, são artistas que ainda se prendem à passagem do local ao global, mas que também têm um repertório pertinente à sensibilidade contemporânea.

Enquanto os repentistas podem desfrutar de referências sólidas de sentido, que os valores da tradição propiciam, as novas formas de expressões culturais estão tentando fugir do aprisionamento dos homens nas fronteiras de suas definiçóes culturais, ao mesmo tempo em que buscando encontrar estabilidade. Um dos importantes teóricos da Identidade na Modernidade Líquida (Bauman, 2005) observa que esses novos movimentos estão buscando a segurança nas raízes do passado, através da idealização do presente. Neste caso, o Rap apresenta-se à procura de uma história estabilizadora ou, pelo menos, respeitada, como tem o repente. O repentista Antônio Lisboa foi preciso em detectar essa necessidade:

O rap é uma cultura que ainda tá em processo inicial, porque o rap tá ensinando o rapper a implantar o verso. O que o rap tá fazendo hoje, a cantoria tá fazendo desde duzentos anos atrás. Essa luta de prisão que o Zé Cláudio falou, o cantador já passou há cem anos atrás, há setenta anos. Quer dizer, por isso hoje a cantoria está numa fase mais áurea, e o rap tá chegando e tá pegando a cantoria numa fase muito áurea. Mas quando nem se falava em rap em São Paulo, os cantadores levaram a cantoria pra São Paulo, e lá era dois cantadores cantando e três quatro nas esquinas esperando a polícia vir. Eles estão começando e a cantoria já fez isso, já teve muita conquista, mas isso a poder de muito sangue, de muito preconceito, de muita luta, de muita perda, e tudo isso teve que passar e muita gente nem sabe de tudo isso que aconteceu. [...] $\mathrm{Na}$ verdade a cantoria tem uma história que precisa ser levada em conta, que o rap tá tentando implantar agora. (Antônio Lisboa).

Para este aspecto, Bauman completa a análise:

$\mathrm{O}$ anseio por identidade vem do desejo de segurança, ele próprio um sentimento ambíguo. Embora possa parecer estimulante no curto prazo, cheio de promessas e premoniçóes vagas de uma experiência ainda náo vivenciada, flutuar sem apoio num espaço pouco definido, num lugar teimosamente, perturbadoramente "nemum-nem-outro", torna-se a longo prazo uma condição enervante e produtora de ansiedade (Bauman, 2005 p. 35).

Por seu turno, os rappers se colocam numa atitude reverencial aos repentistas e não escondem a necessidade de buscar neles uma referência simbólica:

Eu acho mesmo assim que é uma questáo que os repentistas, já partindo pra questão literária da rima, eles tão dez mil anos luz na frente do rap. A gente, todo mundo na cultura rap sabe disso, assim, tira o chapéu porque eles têm uma evoluçáo, aquela questão de métrica pra rima que ainda não aconteceu pro rap, o rap meio que estagnou nisso. A gente tem hoje em dia vários MCs aqui no Nordeste que tentam fazer essa junção, mas que ainda não desenvolveu tanto. Pô, a gente tem ídolos no meio do repente que é o próprio Patativa do Assaré, Zé Limeira, caras assim que qualquer $\mathrm{MC}$ que ler vai ver que eles eram MCs também.

Rap e Repente têm em comum a rima, o improviso, a palavra cantada, o canto falado, isto é, a língua em expressões imprevisíveis. Esse ambiente é um campo fecundo e se cons- 
titui como lugar onde a identidade e a alteridade podem atuar em múltiplos níveis. É o espaço ideal para a negociação. Mas apesar da habilidade em manipular o verbo, rappers e repentistas não tiveram a oportunidade de manipular o contato:

A gente não fica muito à vontade não, eu no meu caso, eu não me sinto muito à vontade não, não chego a mudar o meu eu, o que sou, mas não fico à vontade como quando eu estou numa platéia no sertão que eu sei que todo mundo foi pra prestigiar aquilo ali mesmo, e aqui eu sei que um bocado não veio para ouvir isso aqui. Porque quando você tem aquele público que é auditório mesmo, com prazer, porque quando você vê que o público tá gostando, degustando mesmo, que ele tá com amor, aí você fica à vontade pra cantar bem feliz, interage com mais dez cantadores, o clima é bom. Quando ninguém interage com você, aí você fica se sentindo só (Raimundo Caetano / I Rap e Repente).

Quando a relação das diferenças se dá numa ação mediada por uma instituição, onde o incentivo maior não resultou das próprias movimentaçóes das identidades em questão, a comunicação se torna arbitrária. A situação de imposição impele à auto-afirmação do grupo que se sentiu hostilizado. Consequentemente, o grupo dos excluídos tende a enaltecer as características do eu (identidade) em detrimento das características do outro (alteridade), tal qual ensaia o repentista Antônio Lisboa:

Eu acho que o hip hop como um estilo e cantoria como outro estilo podem subir no mesmo palco, até porque nós já convivemos num mesmo palco com a embolada de coco, com o coco de roda, com a ciranda, com os declamadores, com os aboiadores, que são uma variante da cantoria, tudo isso nós fizemos numa perfeita harmonia, sem problema nenhum, mas sem descaracterizar nem uma coisa, nem outra [...]. Agora eu sou mais a favor de colocar dois cantadores e depois um rapper, no mesmo palco você mostra, vamos dizer, Rogério Menezes e Lourival Vitorino para suas apresentaçóes de cantoria, depois desce os dois e sobe o grupo de rap e faz sua apresentação como combinado, aí você tem como mostrar o rap ao público da cantoria e mostrar a cantoria ao público do rap (Antônio Lisboa).

Por mais que a Identidade esteja em busca de coerência, ela não é fixa, estável, permanente, mas estratégica e posicional. A identidade, quando analisada no campo das relaçóes sociais e das interações entre os seus sujeitos, elucida que a autopercepção do grupo acerca de sua origem, de seu destino, de seus valores e de suas possibilidades de futuro se dá nas relaçôes de contato.

O repente é uma tradição poética e cultural que vem atravessando os tempos e desafiando mudanças culturais e sociais. No dizer de Bauman (2005), a tradição poética do repente corresponderia a expressóes de formas antigas que estão no meio termo de uma postura parcialmente enraizada numa história e no passado comum e noutra parcialmente contingente às situações vividas. Há muito os poetas vêm conseguindo manter discursos e valores, ao passo que se renovam em função das modificaçóes impostas pelas mudanças sociais. Ao repentista não é estranho interagir com diferentes realidades socioculturais, com diferentes expectativas por parte do público. O improviso é tão eficaz quanto a sua regra, e tão criativo quanto a capacidade do verbo, mas é em nome de uma tradição secular que os repentistas pisam cuidadosamente na liquidez dos terrenos indefinidos.

Pela maior permissão de experimentação, os rappers acessaram com mais facilidade a permuta cultural que este evento ofereceu. O Hip Hop se enquadra numa nova tendência artísti- 
ca difundida no mundo todo, que consiste em atualizar ritmos locais a partir da fusão de ritmos decorrentes do fluxo globalizado, como o rock and roll, o black music e os gêneros da música eletrônica (tecno, house, trance). Também por essa flexibilização é que o desafio do rap e repente foi mais ríspido para os repentistas, que encapsulados pela tensão dos desfazimentos de antigas posturas, foram também convidados a introduzir o tempo e o devir necessários à continuidade das identidades. Portanto, identidade e alteridade, nesse encontro de improviso, conduziu seus interlocutores para além da reflexão do "ser" e do "não-ser", ampliando-se à reflexão do que "foi" e do que "será".

\section{Identidade e Multiculturalismo}

A temática do multiculturalismo tem ocupado um lugar de destaque nos debates teóricos da última década. Isto se deve tanto à dinâmica dos movimentos sociais e das reivindicações culturais contemporâneas quanto à intervenção do Estado, atuando como formulador e promotor de políticas de desenvolvimento cultural. Do ponto de vista teórico, fala-se em colapso dos ideais racionalistas, iluministas, universalizadores, o que resulta numa nova perspectiva cultural que rejeita os valores universais em nome dos específicos. Do ponto de vista político, questiona-se a interferência do Estado na construção de critérios culturais e a seleção de valores representativos de uma identidade nacional.

É certo que o conceito de multiculturalismo se prende, por um lado, na polissemia das manifestaçóes culturais, mas ele deve ser considerado no contexto político-social onde emergem reivindicações de políticas culturais. As múltiplas dimensôes das manifestações identitárias no contexto institucional do Estado têm sido apreendidas através da noção de
Multiculturalismo, que tem como objeto ensaiar respostas aos anseios das diferentes práticas sociais e políticas de identidade. Apesar de não usar o termo Multiculturalismo, o debate das políticas e práticas culturais tem problematizado a construção de uma sociedade multiétnica, confrontado diferentes posiçóes quanto aos modos de promover a igualdade de oportunidades.

No plano teórico, questiona-se se os procedimentos até então utilizados não são niveladores demais, construindo as diferenças com base em tipos fixos e estereótipos discriminalizantes; ou excludentes demais, ensacando as diferenças todas num mesmo pacote. O teórico do pós-colonialismo (Hall, 2003) diz que é sempre bom ter cuidado para que as diferenças não sejam integradas num processo de "equivalência formal”, muito próximo da concepção de democracia, em que todos terminam por parecer muito semelhantes. Por outro lado, são as reivindicações de diferenças que fazem surgir os tipos mais sólidos de políticas de Identidade e exclusivismos.

Alguns teóricos já falam no amadurecimento do termo multicultural para o termo intercultural, propondo o tratamento da diversidade não a partir de políticas relativas de aceitação, mas de espaços intersticiais onde estão presentes diversos tensionamentos, espaços de negociação e conflito.

Stuart Hall sugere que o Multiculturalismo seja utilizado não como noção abstrata empregada à identidade da nação, e sim como noção da diferença, em que as diversas "comunidades" que compóem a nação devam interagir concretamente (Hall, 2004). Ao fazer uma análise do modelo multicultural britânico, Hall diz ainda que: "Deve-se tentar construir uma diversidade de novas esferas públicas nas quais todos os particulares serão transformados ao serem obrigados a negociar dentro de um horizonte mais amplo" (Hall, 2003, p. 83). Esse seria um as- 
pecto da ação cultural proposta pelo autor, ou seja, uma política cultural que funcione como vetor motivador capaz de fazer os indivíduos se engajarem num projeto coletivo em que a prática da alteridade seja de fato exercitada.

O I Encontro Nacional de Rap e Repente foi um exemplo preciso de como essa arena de negociaçôes pode ocorrer de fato. Além disso, serviu como parâmetro para analisarmos como a política cultural é capaz de influenciar, num determinado momento, a cultura política dos grupos que ela envolve. O fato é que, num modelo mais geral de multiculturalismo, o Estado sempre procura sintetizar valores populares e conciliar os diferentes interesses, tal qual a figura do juiz que apazigua os conflitos em campo. Em todo caso, o autor supracitado afirma que, do ponto de vista formal ou abstrato, o antagonismo nunca poderá ser resolvido, pois só há uma forma acessível de resolução: as oportunidades de negociação prática.

De modo quase mascarado, vemos insurgir no I Rap e Repente as bases de um conflito relacional. A fim de manter a dignidade do espaço sabotado e pela falta de campos intersticiais de negociaçóes arbitrárias, acaba-se por optar pelo poder da Identidade exclusivista. $\mathrm{O}$ que era para ser uma possibilidade de troca cultural acabou-se tornando uma arena de desencontros e insatisfações. A esse respeito, vale ressaltar a crítica de Marc Augé:

[...] o desaparecimento do laço simbólico, a falta de um dispositivo suscetível de construir alteridade e, além disso, identidade relativa, é flagrante - em uma linguagem institucional, falar-se-á de fracasso de políticas públicas de integração, num caso, e de desmoronamento do Estado, no outro (Marc Augé, 1997, p. 99).

Devemos observar cuidadosamente as propostas de pontes de comunicação entre diferentes culturas. $\mathrm{O}$ estabelecimento de redes a partir de elementos e princípios em comum às culturas em nada garante os resultados do contato. Se, por um lado, fala-se em fomentação de políticas públicas de apoio à diversidade cultural, por outro, a falta de domínio a respeito das diferenças simbólicas fortalece as políticas deterministas de identidade. Não é através da coesão simbólica da realidade brasileira que se chegará ao respeito pela diferença; é preciso amadurecer a discussão acerca da diversidade cultural e suas forças de expressão desiguais e diferentes.

\section{Consideraçóes finais}

O caso do I Encontro Nacional de Rap e Repente, por ter ocorrido em sua primeira versão, é ponto de partida para pensarmos questóes da diversidade em que a linguagem da alteridade se sobreponha à da diferença, na prática e não apenas na teoria. Este é o grande desafio para as políticas públicas fundamentadas em propostas multiculturalistas. De todo modo, o campo dentro do qual o Estado deverá arbitrar é muito mais complexo do que uma ideologia da harmonia; ele deve partir da tensão entre Identidade e Diferença.

Partindo da constatação de que o diálogo intercultural não sobrevive da mera justaposição das formas, acreditamos ser necessária a elaboração de encontros e de espaços onde possam emergir iniciativas de crítica; onde possam ser assumidas as diferenças irreconciliáveis, bem como os denominadores comuns que desafiam as certezas dominantes. Os maiores exercícios a serem motivados devem ser o da aceitação das diferenças verticais e da troca conceitual através de críticas mútuas.

Ao longo do texto tratamos a Identidade enfatizada como um movimento de transformação e não como definição "daquilo que é". Pela relação intrincada entre Identidade e Di- 
ferença podemos concluir que, assim como a Identidade, a Diferença é também indeterminada e instável. Logo, espaços mal-regulados ou políticas mal-definidas, espaços de difícil mobilidade dão margem a disparidades políticas e diferenças que se constituem ao sabor do imprevisto, ou do improviso.

Vimos também que a concepção de identidade permeada pela ideia do idêntico, do igual, dificulta a relação direta com a alteridade e favorece os processos de hierarquização. Todavia, conforme analisamos, é nas situaçóes de contato com o diferente que a Identidade se exaspera. Daí resultam as dificuldades encontradas na prática expansiva da lógica e da política cultural, principalmente quando as diferenças são negligenciadas enquanto fundamentadoras da noçáo do ser. Isto é, quando se nega a informação profunda sobre o "outro" ou quando não são delimitados espaços limítrofes.

O exercício da alteridade é um chamado para todos nós, mas cabe às políticas culturais reconhecerem o desafio de assegurar uma interação plural e, ao mesmo tempo, defender a variedade de formas através das quais as diferenças existem, dando condiçôes para as identidades se expressarem. Em outras palavras, o tratamento institucional igualitário passa pela aceitação da diferença do "outro".

\section{$1^{\text {st }}$ Rap and Repente National Meeting: in} search of a rime between identity and alterity

abstract The change in processes of Identity is part of a more complex change in society. We thus emphasize Identity as a movement of transformation apprehended as a process, not as a fixed point of elaboration. Another discussion concerning cultural identities focuses on the movement of "hybridization", which based on the conflict between cultural loans and contacts calls for a reflection on Identity and Difference. The example of the $1^{\text {st }}$ Rap and Repente National Meeting will thus be used to analyze how Identity is produced by social inter-relations, the reports of rappers and repente poets on the meeting will be used to consider the proposals of cultural policies by the Ministry of Culture which anticipate communication bridges between different cultures, but disregard the aspects of cultural difference and diversity.

keywords Identity. Difference. Diversity. Hybridization. Conflict.

\section{Notas}

O termo "pé-de-parede" refere-se à forma com que os artistas se apresentavam, sentados num tamborete, encostados na parede do estabelecimento comercial, ou na casa de algum apologista que convidou o poeta por ocasião de comemoraçóes como festas de aniversário ou batizado. Esta é tida como a forma mais antiga da cantoria de viola.

2 Para Hall este termo emerge da ideia prática de "uma identidade para cada movimento" (Hall, 2002, p.45).

3 Texto disponível no site oficial do evento: http:// www.raprep.com.br.

4 Um mês após o encerramento do Rap e Repente, conversei com dois integrantes do Núcleo Hip Hop Campina, o MC e produtor George, conhecido como Frequência Zero FHz0, e o DJ e produtor Tiago, mais conhecido como DJ Joh.

5 O PNC foi aprovado como Emenda Institucional em agosto de 2005.

\section{Referências bibliográficas}

AUGÉ, M. Por uma Antropologia dos Mundos Contemporâneos. Rio de Janeiro: Bertrand Brasil, 1997.

AYALA, M. I. N. No Arranco do Grito. Aspectos da Cantoria Nordestina. São Paulo: Atica, 1988.

BAUMAN, Z. Identidade. Rio de Janeiro : Zahar, 2005.

BHABHA, Homi K. O Local da Cultura. Belo Horizonte: Editora da UFMG, 2007. 
CANCLINI. Nestor García Culturas Hibridas. Estratégias para entrar e sair da modernidade. 3ed. São Paulo: EDUSP, 2000. (Ensaios Latino-americanos 1)

Consumidores e Cidadãos. Conflitos multiculturais da globalização. 5 ed. Rio de Janeiro: UFRJ, 2005.

EAgLETON, Terry. A Ideia de Cultura. São Paulo: Unesp, 2005.

GEERTZ, Clifford. Nova Luz sob a Antropologia. Rio de Janeiro: Jorge Zahar Editor, 2001. 247p.

HALL, Stuart. A identidade cultural na pós-modernidade. 7ed. Rio de Janeiro: DP\&A, 2002.

Quem precisa de identidade? In: SILVA, T.T. (org.). Identidade e diferença: a perspectiva dos Estudos Culturais. Petrópolis, RJ: Vozes, 2004. p. 103133.

Da diáspora. Identidades e mediaçóes culturais. Belo Horizonte: Editora da UFMG, 2006.

MARTINS, Paulo Henrique. Cultura, identidade e diferença: Caminhos do novo movimento teórico (Conferência magistral). In: XIII Encontro de Ciências Sociais do Norte e Nordeste-CISO, 2007, Maceió. Anais.... Maceió, 2007.

MINISTÉRIO DA CULTURA, Política Cultural no Brasil 2002-2006: Acompanhamento e Análise. Brasília: MINC, 2007. 220p.

OLIVEIRA, Roberto Cardoso Caminhos da Identidade. Ensaios sobre etnicidade e multiculturalismo. São Paulo; Brasília: Editora UNESP; Paralelo, 2006.

SILVA, Tomaz Tadeu. A produção social da identidade e da diferença. In: . (Org.) Identidade e diferença: a perspectiva dos Estudos Culturais. Petrópolis: Vozes, 2004. p. 73- 102.
O Sujeito da educação: estudos foucaultianos. 4ed. Petrópolis: Vozes, 2000, 258p.

SOUZA, Karlla C. A. A Cantoria de Repente Volta para Casa: Itapetim no Circuito dos Congressos de Violeiros. Dissertação (Mestrado) - Centro de Ciências Humanas Letras e Artes, Universidade Federal da Paraíba, Campina Grande, 2004.

WOODWARD, Kathryn. Identidade e diferença: uma introdução teórica e conceitual. In: SILVA, T.T. (org.). Identidade e diferença: a perspectiva dos Estudos Culturais. Petrópolis: Vozes, 2004. p. 7-71.

UNESCO. Convenção Sobre a Proteção e Promoção da Diversidade das Expressóes Culturais. Texto oficial ratificado pelo Brasil por meio do Decreto Legislativo 485/2006, 32p.

\section{Agradecimentos}

Agradeço ao Núcleo Hip Hop Campina e em especial ao DJ Joh e ao MC Frequência Zero pelas informaçóes concedidas com tanta boa vontade.

Agradeço também aos repentistas Antônio Lisboa, Rogério Menezes, Raimundo Caetano e Lourival Vitorino pela paciência que tiveram com a minha inoportuna presença nos camarins do I Rap e Repente. Gostaria de destacar a contribuição do poeta Edmilson Ferreira, que fez a leitura do texto e teceu comentários sobre o mesmo.

\section{autora Karlla Christine Araújo Souza \\ Doutoranda em Ciências Sociais/UFCG}

Recebido em 30/03/2009

Aceito para publicação em 06/11/2009 